\title{
Etiopatogenia do cisto radicular. Parte I
}

\author{
Luciano Cincurá Silva Santos ${ }^{1}$ \\ Eduardo Antônio G onçalves Ramos² \\ Thiago $M$ artins $M$ eira ${ }^{3}$ \\ Claudia Roberta Leite Vieira de Figueiredo ${ }^{4}$ \\ Jean N unes dos Santos ${ }^{5}$
}

\section{Resumo}

Aslesões periapicais crônicas decorrem principalmentedainfecção dos canais radiculares, devido à doença cárie. Sabe sequeo processo imuno-inflamatório éa base de formação dos granulomas dentáriose cistos radiculares, favorecido pela defesa primária emediado por células como macrófagos eneutrófilos, ou através de uma defesa específica, mediada por linfócitos e células apresentadoras de antígenos, como as Células de Langerhans. 0 presente trabal ho se propõe a apresentar os aspectos gerais sobrea etiopatogenia dos cistos radiculares, cuja complementação a respeito destas lesõese a avaliação morfológica das mesmas serão objeto da segunda parte desteestudo.

Palavras-chave: cisto radicular - etiopatogenia; lesões periapicais.

\section{INT RO DUÇÃO}

As lesões periapicais tipo granuloma dentário e cisto radicular representam entidades muito comuns na clínica odontológica. Sua etiologia principal é a cárie dentária. As endotoxinas bacterianas, bem como as citocinas originadas do processo imuno-inflamatório parecem ter influência no desenvolvimento de tais lesões.

Após a necrose pulpar, a disseminação e a instalação de bactérias no periápice, estimulam e ativam os mecanismos de defesa inata e adquirida, permitindo que eventos vasculares e celulares propiciem o desenvolvimento dos granulomas dentários e cistos radiculares. A literatura mostra que 0 cisto radicular pode surgir a partir de um granuloma dentário preexistente, bem como por indução dos restos epiteliais de M alassez.

Essa formação cística acontece à medida que os elementos epiteliais proliferam, com conseqüente aparecimento de uma cavidade preenchida de material líquido ou semilíquido, eventos esses relacionados aos processos imunoinflamatórios. 1,2, 3, 4

O granuloma dentário constitui uma massa de tecido de granulação associado ao ápice

\footnotetext{
${ }^{1}$ M estre em Clínica O dontológica. Faculdade de O dontologia - UFBA. Salvador - BA

2 D outor em Patologia. Professor de Patologia e Coordenador do Laboratório de Histopatologia. FIOCRUZ. Salvador - BA

${ }^{3}$ Bolsista de Iniciação Científica PIBIC/CN Pq. Faculdade de O dontologia - UFBA. Salvador - BA

${ }^{4}$ D outora em Patologia Bucal. Professora de Patologia - UFPB. João Pessoa - BA

${ }^{5}$ D outor em Patologia Bucal. Professor de Patologia e Coordenador do Laboratório de Patologia Cirúrgica. Faculdade de 0 dontologia

- UFBA. Salvador - BA
}

\section{Correspondência para/Correapondece ta}

Prof. Jean $\mathrm{N}$ unes dos Santos

D epartamento de Propedêutica e Clínica Integrada - UFBA

Av Araújo Pinho, 62 - Bairro: Canela.

40.110-150. Salvador - BA - Brasil.

E-mail: jeanunes@yahoo.com.br 
de um dente sem vitalidade pulpar. ${ }^{5}$ Já um cisto, incluindo o cisto radicular, representa uma cavidade patológica, revestida internamente por epitélio, e é constituído externamente por um tecido fibroso que contém, no seu interior, um material fluido ou semi-fluido. ${ }^{1,6,7,8,9} 0$ conteúdo cístico é muito variado e inclui desde cristais de colesterol até drogas antibióticas. ${ }^{10,11}$

De acordo com a organização Mundial de Saúde $(0 M S)^{12}$, os cistos da região maxilofacial podem ser classificados em odontogênicos e não-odontogênicos. Os odontogênicos podem ser de desenvolvimento ou inflamatórios, sendo o cisto radicular classificado como um cisto odontogênico inflamatório.

O s cistos odontogênicos representam uma das principais causas de destruição óssea nos maxilares. Por isso e pela incidência freqüente dessas lesões na clínica diária e nos diferentes ambulatórios, muitos autores vêm desenvolvendo pesquisas nessa área. ${ }^{3,13}$

\section{ET IO PAT O GÊNESE}

\section{Aspectos $\mathrm{G}$ erais}

0 estímulo crônico de baixa intensidade, desencadeado pelas bactérias e seus produtos, proporciona ao organismo condições de "controlar" a agressão e, dessa forma, a mantê la confinada à região periapical. Sendo assim, as lesões periapicais crônicas são representadas, basicamente, pelos granulomas dentais e cistos radiculares. ${ }^{11}$

O s granulomas dentários são formados devido à penetração de agentes infecciosos bacterianos e irritantes no periápice dental, que proporcionam um aumento do número de fibroblastos, fibrilas colágenas, células endoteliais e capilares, em associação com a hiperemia e edema. Por outro lado, durante 0 período de deposição da dentina radicular, a bainha epitelial de $\mathrm{H}$ ertwig desorganiza-se por apoptose, deixando os restos epiteliais de Malassez, a partir dos quais podem se desenvolver os cistos radiculares, pela presença e ação de citocinas inflamatórias que parecem estimular a divisão dessas células epiteliais, bem como a reabsorção do osso adjacente. 2,3,5,14,15,16
Tentou-se explicar a patogênese do cisto radicular dividindo-a em duas etapas: formação e crescimento. ${ }^{17} \mathrm{~N}$ a formação cística, a proliferação celular interna do granuloma dentário não recebe, por difusão, os nutrientes advindos do estroma circunjacente, necessários para o metabolismo da lesão. Assim, a falta desses nutrientes resulta em degeneração e morte das células centrais do tecido proliferativo, com subseqüente liquefação, provocando uma cavitação no interior da massa patológica. Já o crescimento resultaria da degradação das células centrais, com conseqüente aumento da pressão osmótica interna em comparação com aquela do estroma circundante. Essa diferença de pressão facilitaria internamente 0 acúmulo de líquido, para compensar e balancear a pressão osmótica total. Isso permitiria que a pressão hidrostática interna do cisto aumentasse, com conseqüente compressão do revestimento interno e estímulo à divisão celular. ${ }^{17}$

A presença de fibrina e colesterol sugere que a hemorragia também contribui para 0 crescimento cístico, já que o acúmulo de moléculas de baixo peso molecular, somado a uma inadequada drenagem linfática, determina uma pressão osmótica mais elevada em relação ao soro. ${ }^{18}$

H oje, sabe-se que a formação e a expansão císticas não se devem apenas a essa teoria da pressão osmótica, mas também às propriedades do epitélio cístico, da matriz extracelular e dos componentes bioquímicos das reações imunoinflamatórias. Como descrito anteriormente, 0 estroma circundante, na tentativa de barrar 0 processo de crescimento dessa lesão, reage produzindo fibras colágenas, organizando a cápsula cística. Assim, parte da reabsorção óssea acontece devido à produção de colagenases e prostaglandinas pelos fibroblastos capsulares e pela estimulação osteoclástica associada ao infiltrado inflamatório. ${ }^{3}$ 15, 17, 19, 20

\section{Aspectos imunológicos}

A resposta imune é um fenômeno biológico de proteção para um organismo, mediador de injúrias e, em várias circunstâncias, um mecanismo de reparo. ${ }^{21} \mathrm{Um}$ elemento é necessário para a iniciação dessa resposta: um 
antígeno que, nas infecções periapicais, na maioria das vezes, é de origem bacteriana. ${ }^{21}$ Reações imunológicas em doenças periapicais crônicas possuem tanto um caráter inespecífico quanto específico. 0 primeiro é caracterizado por alterações vasculares e produção de mediadores químicos inflamatórios, enquanto o segundo pode ser classificado em dois tipos: humoral e celular. A resposta humoral pode ser mediada pelo complexo antígeno - anticorpo ou reações I gE dependentes. Já a resposta celular é mediada principalmente pelos linfócitos $\mathrm{T}$ e B. 22,23

Todo processo imunológico existente nessas lesões periapicais inicia-se com a agressão tecidual, normalmente proporcionada pela infecção bacteriana. 0 predomínio de uma microbiota anaeróbica gram negativa no interior do canal dentário infectado favorece a produção de lipopolissacarídeos e endotoxinas na região periapical. O s lipopolissacarídeos ativam 0 sistema complemento pela via alternativa, produzindo peptídeos quimiotáticos como $\mathrm{C} 5 \mathrm{a}$, estimulando também as células epiteliais e endoteliais do ligamento periodontal a produzirem citocinas importantes para 0 desenvolvimento das lesões periapicais crônicas. Do mesmo modo, as endotoxinas bacterianas exercem a sua atividade biológica ao promover a mitose de células epiteliais, bem como 0 estímulo à produção de citocinas pelo tecido conjuntivo circundante e pelas próprias células inflamatórias. ${ }^{2,3}$

0 contínuo influxo de bactérias e seus produtos para o periápice induzem a ativação coordenada de mecanismos imunoinflamatórios. Esse processo de combate ao microorganismo também favorece 0 dano tecidual, devido à produção de citocinas produzidas por células de defesa como macrófagos, neutrófilos, mastócitos, células apresentadoras de antígeno, linfócitos e mediadores químicos provenientes da defesa primária da inflamação. 0 entendimento do equilíbrio dinâmico de defesa e destruição deverá ser compreendido para que os sinais clínicos e sintomas das várias lesões periapicais sejam esclarecidos. ${ }^{2}$

A fase inicial da inflamação periapical é caracterizada pela presença de neutróflios seguida de macrófagos que possuem a função precípua de proteção contra infecção e limpeza. Além disso, eventos bioquímicos controlados por mediadores químicos, liberados basicamente por mastócitos, bem como e a produção de citocinas e fatores de crescimento, liberados por macrófagos, linfócitos, neutrófilos e mastócitos, constituem 0 ambiente tecidual em destruição. ${ }^{2}$, 3, 24

D entre as células representantes da defesa primária, encontram-se os macrófagos. São células de defesa predominantes no granuloma dentário, representando $46 \%$ das células inflamatórias presentes. Eles atuam tanto na imunidade inespecífica quanto na adquirida. A ativação dessas células em um granuloma dentário parece ocorrer por citocinas produzidas por linfócitos $T$ ativados por antígenos, por endotoxinas, ou por ambos os processos. ${ }^{4,25}$

Recentes estudos em animais atímicos têm mostrado que os granulomas dentários se desenvolvem independentemente de linfócitos T. Essa observação revela a possível relação que os macrófagos ativados possuem na formação de lesões periapicais, possivelmente pela produção de citocinas como IL-1 e T N Falfa, que estimulam a reabsorção óssea, pela produção de metaloproteases como colagenase e elastase, e de prostaglandinas que também contribuem para a destruição tecidual da região periapical. ${ }^{4}$ 25

As células fagocíticas, quando ativadas por bactérias ou outros estímulos como C $5 \mathrm{a}$, leucotrienos (LTB4) e citocinas, experimentam um aumento no consumo de oxigênio e produzem radicais livres provenientes desse oxigênio consumido. ${ }^{2} 0$ s radicais livres, além de promoverem a morte bacteriana, causam dano ao tecido circunjacente.

Recentemente, estudando a expressão de uma enzima citosólica independente do cálcio eisoforme do óxido nítrico (iN O S- óxido nítrico sintase induzível), descobriu-se imunorreatividade para essa enzima em macrófagos, linfócitos, células endoteliais do tecido de granulação, epitélio de lesões periapicais, como cistos radiculares, e em pouca quantidade nos restos epiteliais de $\mathrm{M}$ alassez. ${ }^{26}$ Esses dados demonstram que radicais livres parecem estar envolvidos em processos inflamatórios e que 
talvez participem do mecanismo de ativação e proliferação da camada epitelial, favorecendo a progressão das lesões periapicais inflamatórias.

0 utros mediadores inflamatórios, tais como histamina, cininas eserotoninas, provocam vasodilatação, a menos que um estímulo autônomo os anule. Como efeito direto desses mediadores pode-se citar a constricção dos músculos lisos dos vasos sanguíneos. Essa constricção possibilita a abertura reversível das junções entre as células endoteliais, permitindo a passagem da solução de plasma e polimorfonucleares através da barreira vascular, causando dor quando da compressão nervosa periapical, pelo acúmulo de líquido local, bem como pela produção de citocinas liberadas pelas células em diapedese. Esses mediadores são liberados principalmente durante o período inicial da inflamação, através de células como mastócitos e basófilos. ${ }^{27}$

$\mathrm{N}$ a maioria das vezes, a resposta primária, através de fagócitos, componentes do sistema complemento e mediadores químicos, é suficiente para a eliminação do antígeno, possibilitando ao organismo condições para um reparo tecidual. Caso contrário, instala-se uma inflamação crônica, caracterizada por uma resposta imunológica humoral e celular específica. Esses aspectos são característicos das lesões periapicais aqui estudadas, onde as células T predominam. ${ }^{2}, 3,11,22,23,24$

A população de células $T$ presentes no desenvolvimento de lesões periapicais após indução de imunossupressão foi analisada. Após a infecção de oito gatos com o vírus da imunodeficiência felina (FIV) e o controle de outros oito, livres de infecção, através da técnica imuno-histoquímica, pôde-se observar um decréscimo significativo da população de células T CD 4+ no grupo teste, enquanto a população de células T CD 8+ não apresentou diferença estatística entre os dois grupos. A infecção pelo vírus da imunodeficiência felina resultou em um decréscimo da contagem de CD 4+ em lesões periapicais do grupo teste; contudo, a inflamação e a progressão da lesão apresentaramse comparáveis às do grupo controle. ${ }^{28}$
Ao estudar a distribuição de linfócitos CD 8+ (supressor) e CD 20+ (linfócito B) em noventa lesões periapicais inflamatórias constituídas por abscesso crônico, cisto radicular abscedado e cisto radicular convencional, através da técnica imuno-histoquímica, observou-se a presença difusa desses linfócitos nas lesões. Os linfócitos CD 8+ e CD 20+ estavam presentes nas lesões periapicais, independentemente da existência ou não de proliferação epitelial. Concluiu-se, assim, que a presença do antígeno bacteriano no sistema de canal radicular e periápice é decisiva no aparecimento das células T. ${ }^{29}$

O CD 57 é um antígeno expresso em indivíduos saudáveis, associado ao linfócito CD $3+$ e células $N$ atural Killer. Vários estudos têm demonstrado um efeito imunossupressor quando essa molécula é detectada no tecido estudado. D essa forma, comparou-se a expressão desse antígeno de superfície em cistos radiculares com epitélio hiperplásico e atrófico. Através do método da estreptavidina-biotina, os autores utilizaram vinte casos de cisto radicular previamente classificados com epitélio atrófico ou hiperplásico. Foi considerado atrófico aquele epitélio composto de duas a dez camadas de células com formato plano e cápsula plana. A forma hiperplásica deveria possuir várias camadas celulares e contorno epitelial e capsular ondulado. Foi achada uma percentagem significativamente maior do CD 57 em cistos radiculares com epitélio atrófico, apesar de 0 infiltrado inflamatório não ser estatisticamente significantequando correlacionado aos dois tipos de epitélio. ${ }^{30}$

\section{CONCLUSÃO}

Por fim, percebe-se que, além dos eventos bioquímicos e celulares da inflamação, a defesa humoral e celular também estão envolvidas no desenvolvimento dos cistos radiculares. Entretanto, outras substâncias que controlam tal resposta biológica merecem ser destacadas, como é o caso das citocinas, as quais serão devidamente avaliadas, na Parte II deste estudo. 


\title{
Radialar get's fiqpathoggic Part I
}

\begin{abstract}
Periapical lesions such as dental granulomas (DGs) and radicular cysts (RCs) are common entities in dental practice. Their main etiology is dental caries. Bacterial endotoxins, as well as cytokines originating from the immunoinflammatory process, seem to influence the development of these lesions. After pulp necrosis, the dissemination and installation of bacteria in the periapex stimulate and activate innate and acquired defense mechanisms, with vascular and cellular events leading to the development of DGs and RCs. The present paper, in the first article, presents etiopathogeny of the Radicular Cyst. In the other paper, second part, it will be complemented with incidental information about this lesions and your morphologics appearance.
\end{abstract}

Keywords Radicular cyst - Etiopathogenic. Periapical lesions.

\section{REFERÊNCIAS}

1 HISATOMI, M. et al. MR imaging of epithelial cysts of the oral and maxillofacial region. Eur. J. Radiol., Limerick, v.48, p.178182, 2003.

2 MÁRTON, I. J; KISS, C. Protective and destructive immune reactions in apical periodontitis. 0 ral Microbiol. Immunol., Copenhagen, v.15, p.139-150, 2000.

3 MEGHJI, S. et al. The role of endotoxin and cytokines in the pathogenesis of odontogenic cysts. Arch. O ral Biol., Oxford, v.41, n.6, p.523-531, 1996.

4 PIATTELLI, A. et al. CD la-positive cells in odontogenic cysts. J. Endod., Baltimore, v.28, n.4, p.267-268, 2002.

5 MELO, F.C.C. et al. Granuloma periapical: análise de 150 casos. R. Bras. Patol. 0 ral, N atal, v.2, n.2, p.2-7, 2003.

6 GÁLVEZ-GASTÉLU M , F.J.; SAN D OVALRODRÍGUEZ, A.S; ARMENDÁRIZBORUNDA, J. EI factor de crecimiento transformante $b$ como blanco terapéutico. Salud Publica M éx., Cuernavaca, v.46, n.4, p.341350, 2004.

7 N AIR, P.N.R. N ew perspectives on radicular cysts: do they heal?. Int. Endod. J., London, v.31, p.155-160, 1998.
8 NEVILLE, B.W. et al. Patologia oral e maxilofacial. Rio de Janeiro: Guanabara Koogan, 1998.

9 SILVA, F.M ; BARONI, E.J; CABRAL, R.J.B. Abordagem do tratamento de lesões císticas. $\mathbf{R}$. 0 dontol. Araçatuba, Araçatuba, v.23, n.1, p.3337, 2002.

10 AKIM OTO, Yoshiaki, et al. Ampicillin concentrations in radicular cysts following a single oral administration of bacampicillin. $\mathbf{G}$ en. Pharmacol., Exeter, v.24, n.4, p.895-898, 1993.

11 VIER, F.V; FIGUEIRED O, J.A.P. Prevalence of different periapical lesions associated with human teeth and their correlation with the presence and extension of apical external root resorption. Int. Endod. J., London, v.35, p.710-719, 2002.

12 KRAMER， I.R.; PINDBORG， J.J.; SHEAR, M. The WHO histological typing of odontogenic tumours; a commentary on the second edition. Cancer, N ew York, v.70, n.12, 1992.

13 TAYLOR, A.M. et al. Quistes odontogénicos: análisis de 856 casos. Med. O ral, Valencia, v.7, p.89-96, 2002. 
14 KATCHBURIAN, E.; ARANA, V. $H$ istologia e embriologia oral: texto: atlas. São Paulo: Panamericana, 1999.

15 N ICKO LAYCHUK, B. et al. Evidence for a role of mitogen-activated protein kinases in proliferating and differentiating odontogenic epithelia of inflammatory and developmental cysts. O ral Surg. O ral Med. O ral Pathol., St. Louis, v.93, n.6, p.720-728, 2002.

16 RUIZ, P.A. et al. Fatores relacionados à regressão não-cirúrgica dos cistos radiculares. R. Brás. Patol. O ral., N atla, v.2, n.1, p.3946, jan./mar. 2003.

17 WARD, J.P. et al. A mathematical model of the dynamics of odontogenic cyst growth. Anal. Q uant. Cytol. H istol., St. Louis, v.26, n.1, p.3946, 2004.

18 YASH IM A, M .; OGURA, N .; ABIKO, Y. Studies on cholesterol accumulation in radicular cyst fluid-origin of heat stable cholesterol binding protein. Int. J.

Biochem., Oxford, v.22, n.2, p.165-169, 1990.

19 OLIVEIRA, M.D.C. et al. Tenascin and fibronectin expression in odontogenic cysts. J. O ral Pathol. Med., Copenhagen, v.33, p.354359, 2004.

20 PIATTELLI, A. et al. Expression of transforming growth factor-beta 1 (TGF-b1) in odontogenic cysts. Int. Endod. J., London, v.37, p.7-11, 2004.

21 TORABINEJAD, M.; BAKLAND, L.K.Immunopathogenesis of chronic periapical lesions. 0 ral Surg. 0 ral Med. 0 ral Pathol., St. Louis, v.46, n.5, p.685-699, 1978.
22 NEVIN S, A.J. et al. Sensitization via IgEmediated mechanism in patients with chronic periapical lesions. J. Endod., Baltimore, v.11, n.5, 1985.

23 STASHEN KO, P.; TELES, R.; D 'SO UZA, $R$. Periapical inflammatory responses and their modulation. C rit. Rev. 0 ral Biol. Med., Alexandria, v.9, n.4, p.498-521, 1998.

24 WALKER, K.F. et al. Cytokine expression in periapical granulation tissue as assessed by immunohistochemistry. Eur. J. O ral Sci., Copenhagen, v.108, p.195-201, 2000.

25 METZGER, Z. M acrophages in periapical lesions. D ent. Traumatol., Copenhagen, v.16, p.1-8, 2000.

26 SUZUKI, T. et al. Expression of inducible nitric oxide synthase and heat shock proteins in periapical inflammatory lesions. J. O ral Pathol. Med., Copenhagen, v.31, p.488-493, 2002.

27 SI Q UEIRA JÚ N IO R, J.F.; D ANTAS, C.J.S. Inflamação: aspectos biodinâmicos das respostas inflamatória e imunológica. Rio de Janeiro: Pedro I, 1996.

28 LEVINE, D.F. et al. The effect of FIV infection on CD 4+ and CD $8+$ counts in periradicular lesions. Int. Endod. J., London, v.34, p.586-593, 2001.

29 PHILIPPI, C.K et al. Distribution of CD 8 and CD 20 lymphocytes in chronic periapical inflammatory lesions. B raz. D ent. J., Ribeirão Preto, v.14, n.3, p.182-186, 2003.

30 MOREIRA, P.R. et al. CD 57+ cells in radicular cyst. Int. Endod. J., London, v.33, p.99-102, 2000. 